\title{
Visual and social determinants of shock-elicited aggressive responding in rats*
}

\author{
DONALD H. THOR and WILLIAM B. GHISELLI \\ Edward R. Johnstone Training and Research Center \\ Bordentown, New Jersey 08505
}

\begin{abstract}
Light and dark reared, social and isolate housed, male Long-Evans hooded rats were tested in bright and dim light for aggressive response to footshock. Test lighting and socialization main effects were significant, with greater fighting in dim light than in bright light and greater fighting by isolates than by socially housed animals. Test lighting interacted with prior visual experience and socialization interacted with past and present illumination variables. The results suggest an inhibitory effect of test illumination dependent upon prior social and visual-experience.
\end{abstract}

The importance of posture and related threat (Knutson \& Hynan, 1972; Reynierse, 1971; Vernon, 1969) would appear to implicate visual cues as significant variables in shock-elicited aggression of rats. Flory, Ulrich, and Wolff (1965) investigated the influence of visual impairment by fitting leather hoods over the heads of their Ss. The rats were paired and given shocks over repeated sessions with and without the hoods in place. Hooding decreased fighting by approximately $50 \%$. In a second experiment, a pair of blinded rats fought $27 \%$ less than prior to blinding; when also devibrissaed, the same pair fought at lower levels. The decrease in fighting originally noted with the use of hoods was attributed to both visual and tactual sensory restriction. More recently, Bugbee and Eichelman (1972) have compared pre- and postoperative fighting of blinded, devibrissaed, and bulbectomized rats. Contrary to the results of Flory et al (1965), no decrement in fighting was observed after blinding. Bulbectomized rats fought at near preoperative levels, while devibrissaed rats fought significantly less. Olfactory and visual factors were presumed to have a minor, if any, role in conspecific aggression.

The present investigation sought to assess the role of past and present illumination on shock-elicited aggression. Visual history was manipulated by housing animals in light or darkness, and immediate visual cues were examined by testing in bright or very dim light. Prior social history (isolate or group housing) and aggressive experience (successive fights) were also examined for interactive effects with illumination variables.

\section{METHOD}

Subjects

Ss were 48 male Long-Evans hooded rats.

*Supported by NIH Research Grant MH 21577-01.

\section{Apparatus}

The fighting chamber, a $20 \times 20 \times 20 \mathrm{~cm}$ box of wood and Plexiglas, was enclosed within a fan ventilated light- and sound-attenuating chamber having a viewing portal and a $100-\mathrm{W}$ incandescent lamp (mounted in a recessed ceiling fix ture) that illuminated the fighting chamber. The grid floor of the fight chamber consisted of $1 / 4$-in. brass rods spaced $5 / 8$ in. apart. Constant current shock was delivered from a Lafayette A-615A shock source through a Lafayette 5820 neon grid scrambler.

\section{Procedure}

All Ss were reared from birth with their littermates in constant darkness until weaning. At weaning, female pups were culled and the remaining male pups were randomly assigned to group pan cages containing four Ss each. At 45 days of age, half $(\mathrm{N}=24)$ were removed to a separate colony and housed under constant (24-h) fluorescent illumination (approximately $300 \mathrm{~lx}$ ). Of the remaining dark housed $S s$, half $(N=12$ ) were placed in individual pan cages, while the other half remained in group pan cages. Similarly, half of the light housed $S s(N=12)$ remained in group pan cages of four rats each, while the other half were placed in individual rack mounted wire cages.

At 90-100 days of age, all Ss began behavioral testing. Half of the Ss in each type of lighting and cage housing condition were selected to form pools of Ss containing six rats each, which were tested in bright light (100-W incandescent bulb at $120-\mathrm{V}$ ac, $1180 \mathrm{~lx}$ at fight cage floor). The remaining Ss were also formed into pools and tested in dim light $(100-\mathrm{W}$ incandescent lamp at $25-\mathrm{V}$ ac through a red filter, $2 \mathrm{~lx}$ at fight cage floor). To maintain comparable partner familiarity (cf. Galef, 1970) between isolate pairs and social pairs, socially housed Ss were only paired with socially housed strangers (noncagemates). All Ss fought in five sessions each, spaced $48 \mathrm{~h}$ apart. Round-robin testing allowed each member of a pool to fight all other members and provided a new partner on each test session. A session consisted of 50 shocks $(2.0 \mathrm{~mA}, 0.5 \mathrm{sec})$, spaced $8 \mathrm{sec}$ apart. After each test session, Ss were returned to their respective light or dark colonies.

An attack was defined after Eichelman (1971) and required directed movement by at least one member of the pair toward the opponent, resulting in contact and followed by at least one of the following behaviors: biting, sparring, upright attack posture, or submissive posturing. Two observers independently recorded attacks, with the stipulation that no more than one attack was scored following each shock. Attacks were registered on a printing counter and fighting was expressed as the percentage of shocks effective in eliciting attack. 

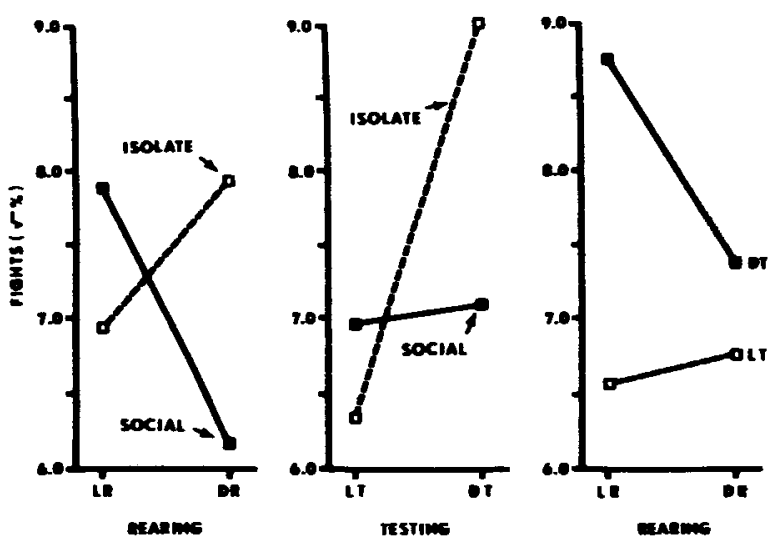

Fig. 1. Significant interactions: left panel, Rearing Illumination by Socialization; center panel, Test Illumination by Socialization; right panel, Rearing Illumination by Test Illumination.

For purpose of statistical analysis, a square-root transformation was performed on the percentage measure of fighting due to its negatively skewed frequency distribution. The round-robin testing was analyzed by assigning the fighting score for a pair of $S$ s to each member; individual scores on repeated test sessions (bouts) were treated as a within-S variable.

\section{RESULTS}

Pairs tested in dim light fought more than pairs tested in bright light $(F=19.27, \mathrm{df}=1 / 40, \mathrm{p}<.001)$ and isolated rats fought more than socially housed rats $(\mathrm{F}=4.12, \mathrm{df}=1 / 40, \mathrm{p}<.05)$. Figure 1 indicates the latter finding was modified by rearing illumination $(\mathrm{F}=12.37, \mathrm{df}=1 / 40, \mathrm{p}<.005)$ and test illumination $(F=16.04, d f=1 / 40, p<.001)$. Dark rearing decreased fighting of socially experienced Ss (Fig. 1, left panel) and increased fighting of isolates. The interaction between socialization and test lighting conditions indicated that fighting of light tested isolates was depressed, while the fighting of dark tested isolates was elevated, relative to socially reared pairs (Fig. 1, center panel). The light conditions during rearing and those present during testing also interacted $(F=6.27$, $\mathrm{df}=1 / 40, \mathrm{p}<.05)$; while light testing depressed fighting and dark testing enhanced attack, it did so more for light reared than for dark reared Ss (Fig. 1, right panel). Finally, there was a significant increment in fighting over repeated testing sessions $(F=4.43, d f=1 / 160$, $p<.005)$, and this change interacted with social-isolate housing conditions $(F=3.70, \mathrm{df}=4 / 160, \mathrm{p}<.01)$. As seen in Fig. 2, isolates fought less than socially reared Ss on the first testing session, and the subsequent increase in fighting over repeated test sessions was more abrupt for isolates than for the socially reared Ss.

\section{DISCUSSION}

The higher rates of fighting under visually attenuated conditions of the present experiment contrast with those reported for blinded rats (Flory et al, 1965; Bugbee \& Eichelman, 1972). The former study reported the behavior of a single pair of rats and, as such, may have been unique. In the latter study, blinded Ss may have reached near asymptotic levels of fighting and further increment was unlikely. Less fighting in bright light in the present study suggests that visual cues may play an inhibitory role in shock-elicited aggression. Support for this position may be found in a report by Reynierse (1971), who demonstrated that the frequency of aggression-related postures elicited in rats shocked singly decreased when the rats were allowed visual, but not physical, contact with another rat.

The higher rates of fighting among isolates agrees with an earlier report by Creer and Powell (1971). An initial report by Hutchinson, Urich, and Azrin (1965) that isolates fight less than socially housed rats (Experiment 2) is not inconsistent with the present study. They gave a single test session to their Ss and, as seen in Fig. 2, the present isolates also fought less on the first session, higher levels being obtained only from the second session on. A second report of lower fighting in isolates (Hutzell \& Knutson, 1972) contrasts sharply with the present results, particularly in view of the similar procedures used in each. The major difference appears to be the large increment in fighting over sessions shown by isolates in the present study; the socially reared animals had a slightly lower but generally comparable level of fighting. The resolution may lie in differences in rearing or test lighting conditions (unspecified by Hutzell and Knutson), since the present experiment demonstrates these factors to differentially affect social and isolate Ss.

The importance of test illumination in the measurement of aggressive behavior of rodents has recently been underscored by Klein, Howard, and DeFries (1970). They proposed that some inconsistency in the literature regarding dominance of highly inbred strains of mice can be attributed to levels of test

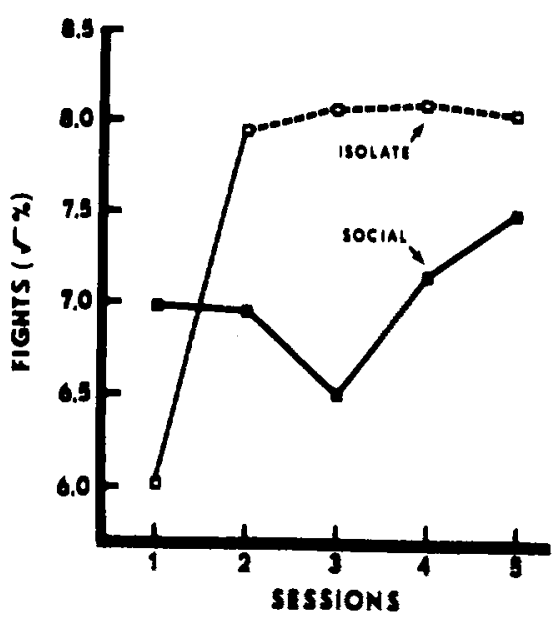

Fig. 2. Interaction of social experience with repeated bouts of fighting. 
illumination and have indicated that albino and pigmented strains of mice display differential aggressive behavior according to level of illumination. Similar strain comparisons in rats, with appropriate control for social experience and illumination history. would appear most instructive.

In general, the influence of test illumination was substantial and had as great an effect on fighting as did the socialization variable of 7 weeks isolation. Isolates were more influenced by test illumination than were socially experienced animals, and light reared Ss were more influenced by test illumination than were dark reared Ss. Test illumination is more significant for light reared than for dark reared rats, and dark tested isolates fight more than light tested isolates. The evidence implicates a visual cue function that inhibits fighting and appears related to previous visual experience. The most striking implication is simply that a considerable body of current experimental evidence may be confounded with unreported illumination variables.

\section{REFERENCES}

Bugbee. N. M., \& Eichelman, B. S., Jr. Sensory alterations and aggressive behavior in the rat. Physiology \& Behavior, 1972, 8, 981-985.

Creer, T. L., \& Powell, D. A. Effects of age and housing conditions on shock-induced aggression. Psychonomic Science, $1971,22,259-261$.

Eichelman, B. S. Effects of subcortical lesions on shock-induced aggression. Journal of Comparative \& Physiological Psychology, 1971, 74, 331-339.

Flory, R. K., Ulrich, R. E., \& Wolff, P. C. The effects of visual impariment on aggressive behavior. Psychological Record, $1965,15,185-190$.

Galef, B. G. Stimulus novelty as a factor in the intraspecific pain-associated aggression of domesticated rats. Psychonomic Science, 1970, 18, 21

Hutchinson, R. R., Ulrich, R. E., \& Azrin, N. H. Effects of age and related factors on the pain-aggression reaction. Journal of Comparative \& Physiological Psychology, 1965, 59, 365-369.

Hutzell, R. R., \& Knutson, J. F. A comparison of shock-elicited fighting and shock-elicited biting in rats. Physiology \& Behavior, 1972, 8, 477-480.

Klein, T. W., Howard, J., \& DeFries, J. C. Agonistic behavior in mice: Strain differences as a function of test illumination. Psychonomic Science, 1970, 19, 177-178.

Knutson, J. F., \& Hynan, M. T. Influence of upright posture on shock-elicited aggression in rats. Journal of Comparative \& Physiological Psychology, 1972, 81, 297-306.

Reyniezse, J. H. Submissive postures during shock-elicited aggression. Animal Behaviour, 1971, 19, 102-107.

Vernon, W. M. Relation of postural threat to incidence of pain-elicited fighting. Proceedings of the 77 th annual convention, APA, 1969, Part 2, 95-96.

(Received for publication July 6, 1973; accepted October 31, 1973.) 